\author{
Luis Carlos Martínez Fernández e Ignacio Molina de la Torre \\ Departamento de Geografía. Universidad de Valladolid
}

\title{
Docencia e investigación a través del análisis y la fotointerpretación del territorio. Los paisajes del Guadarrama (Segovia)
}

\section{Resumen}

El estudio del paisaje ofrece una utilidad pedagógica a tener muy en cuenta en la formación universitaria de magisterio. De este interés didáctico deriva la atención prestada a los paisajes de la Sierra de Guadarrama (Segovia), presentándose una experiencia docente e investigadora para la adquisición de competencias en materia geográfica a partir del análisis y la fotointerpretación de este territorio.

\section{RÉSUMÉ}

L'enseignement et la recherche par l'analyse et la photointerprétation du territoire. Les paysages du Guadarrama (Segovia, Espagne).- L'étude du paysage fournit un outil pédagogique à prendre en compte dans l'enseignement universitaire pour la formation des maîtres. De cet intérêt didactique découle l'attention sur les paysages de la Sierra de Guadarrama (Segovia, Espagne) dans ce travail. Nous présentons une expérience en enseignement et en recherche pour l'acquisition de competences en géographie à partir de l'analyse et de la photointerprétation de ce territoire.

\section{PRESENTACIÓN Y PREMISAS DEL TRABAJO}

\section{CONTEXTO Y OBJETIVOS: LA FORMACIÓN GEOGRÁFICA DE MAESTROS EN EDUCACIÓN PRIMARIA}

$L$ a primera aproximación al aprendizaje de la geografía se presenta en el sistema educativo español durante

\footnotetext{
${ }^{1}$ Este artículo forma parte de los resultados del proyecto de investigación $\mathrm{Di}$ seño de un sistema de localización de fotografías aéreas históricas (España). Aplicaciones a la docencia, la investigación, el planeamiento, la ordenación del territorio y los estudios de paisaje (CSO2012-32428), financiado por el Ministerio de Economía y Competitividad, y cuyo investigador principal es Felipe Fernández García.
}

\section{ABSTRACT}

Teaching and research through the analysis and territorial photointerpretation. Guadarrama landscapes (Segovia, Spain).- The study provides an educational landscape utility to take into account in university education training. This didactic interest derives attention to the landscapes of the Sierra de Guadarrama (Segovia, Spain), presenting a teaching and research experience to the acquisition of skills in geographical terms from the analysis and photointerpretation of this territory.

\section{Palabras Clave/Mots clé/Keywords}

Didáctica geográfica, análisis territorial, fotointerpretación, Sierra de Guadarrama.

Didactique géographique, analyse territoriale, photointerprétation, Sierra de Guadarrama.

Geographical didactic, territorial analysis, photointerpretation, Sierra de Guadarrama.

los años iniciales de formación académica en la etapa de educación primaria. Es a través de las materias de ciencias sociales y de ciencias de la naturaleza, tal y como se reformulan en la Ley Orgánica para la Mejora de la Calidad Educativa (LOMCE) $)^{2}$, como se construye un ámbito de conocimiento escolar en torno a la naturaleza y a la sociedad, que son las dos dimensiones inherentes al objeto de estudio de la geografía académica, esto es, el espacio geográfico.

\footnotetext{
${ }^{2}$ Ley orgánica 8/2013, de 9 de diciembre, para la Mejora de la Calidad Educativa. BOE, de 10 de diciembre de 2013 .
} 
Sin embargo, una de las carencias más significativas de nuestro sistema educativo es, precisamente, la de la enseñanza renovada (acorde con lo que son los fundamentos epistemológicos de la disciplina) de la geografía. Atrás debe quedar esa concepción primaria, acientífica y errada que la considera una materia meramente memorística, que tiene que ver, en exclusiva, con las localizaciones espaciales y el aprendizaje de mapas. La geografía no es la «ciencia» de las localizaciones (por más que desde esta consideración sí que pueda ser identificada con un cierto saber o cultura geográfica), es la ciencia de las relaciones espaciales, la que trata de explicar y de hacer comprensibles las claves de la organización de los entornos sociales, a escalas globales, regionales y locales.

En septiembre de 2013, en el congreso europeo de geógrafos celebrado en Roma, se firmaba la declaración (que lleva el nombre de esa capital) que pide a los gobiernos de los distintos Estados europeos que intensifiquen los programas de geografía en sus sistemas de enseñanza, al tiempo que incidía, expresamente, en la mejora de la preparación geográfica de los docentes, y entre ellos, muy particularmente, de los maestros de enseñanza primaria $^{3}$. Un problema de dificil solución en nuestro país y que tiene que ver con los enormes déficits detectados en este tipo de formación dentro de los planes de estudio universitarios de magisterio o educación.

En efecto, nuestra experiencia impartiendo la asignatura Geografía y Sociedad, de cuarto curso del Plan de Estudios de Grado en Educación Primaria por la Universidad de Valladolid (Facultad de Educación de Segovia), nos ha permitido detectar, con claridad, los déficits que los estudiantes universitarios de magisterio, al menos los pertenecientes al alma mater vallisoletana, tienen con respecto al conocimiento de la geografía, como disciplina académica y universitaria. Y que no concuerda con la importancia otorgada a la geografía escolar al analizar los contenidos que el currículo educativo contempla para las mencionadas materias de ciencias sociales y de ciencias de la naturaleza ${ }^{4}$.

\footnotetext{
${ }^{3}$ Rome Declaration on Geographical Education in Europe. IV Eugeo Congress 2013. En la misma línea de preocupación por la enseñanza de la geografía se situó el debate promovido por la Comisión Internacional de Educación Geográfica en el seno de la Conferencia de la Unión Geográfica Internacional celebrada en agosto de 2014 en Cracovia, del que se deriva el documento Looking for an international strategy for geography education, que fue tema central de la Conferencia de Moscú en agosto de 2015

${ }^{4}$ El currículo oficial de la educación primaria aparece contemplado en el real decreto 126/2014, de 28 de febrero, por el que se establece el currículo básico de la educación primaria ( para el caso de Castilla y León, se contiene en la Orden Edu/519/2014, de 17 de junio, por la que se establece el currículo y se regula la implantación, evaluación
}

Partiendo del convencimiento de que es necesario conocer para poder enseñar, la asignatura Geografía y Sociedad pretende proporcionar a los futuros maestros las claves explicativas para la comprensión de los elementos y procesos geográficos, con vistas a facilitar unos contenidos que se creen elementales para su formación académica y posterior ejercicio profesional. Desde esta consideración, la asignatura tiene como objetivo profundizar en el estudio del espacio más cercano (la comunidad autónoma de Castilla y León), como entorno de referencia con contenidos específicos dentro del currículo educativo, siguiendo como hilo argumental el de la interpretación de los paisajes geográficos de Castilla y León. Con ello se persigue (1) afianzar la reflexión sobre el paisaje, en cuanto que es un concepto capaz de aglutinar y articular el conocimiento del medio natural, social y cultural; (2) familiarizar a los estudiantes con la diversidad y complejidad territorial y paisajística castellana y leonesa; y, por último, (3) establecer un vínculo operativo, que se presume fecundo y provechoso, entre la geografía que se cultiva en la universidad y la que se ha de enseñar en la escuela.

\section{El paisaje Como objeto de estudio Y ENSEÑANZA DE LA GEOGRAFÍA}

Los geógrafos han venido utilizando el término «paisaje» desde finales del siglo XIX para designar la configuración visible que tienen los hechos geográficos: la forma y fisonomía que toma la estructura del espacio terrestre en un «lugar» determinado; en suma, la imagen del territorio (Ortega, 2000). La construcción de un concepto científico a partir de la noción cultural de paisaje constituye, así, uno de los rasgos más relevantes de la geografía moderna. El relieve, el clima, el agua o la vegetación son los elementos naturales del paisaje geográfico. La población y su distribución, las actividades económicas y su localización, los recursos y aprovechamientos son los componentes que de siempre han conformado los caracteres humanos de la organización paisajística.

Sin embargo, diversos han sido los «discursos del paisaje», es decir, los modos en que los geógrafos se han aproximado a su entendimiento. El discurso predominante ha sido el de identificar al paisaje con la naturaleza y, en consecuencia, los paisajes por excelencia han

\footnotetext{
y desarrollo de la educación primaria en la Comunidad de Castilla y León (BOCYL, de 20 de junio de 2014).
} 


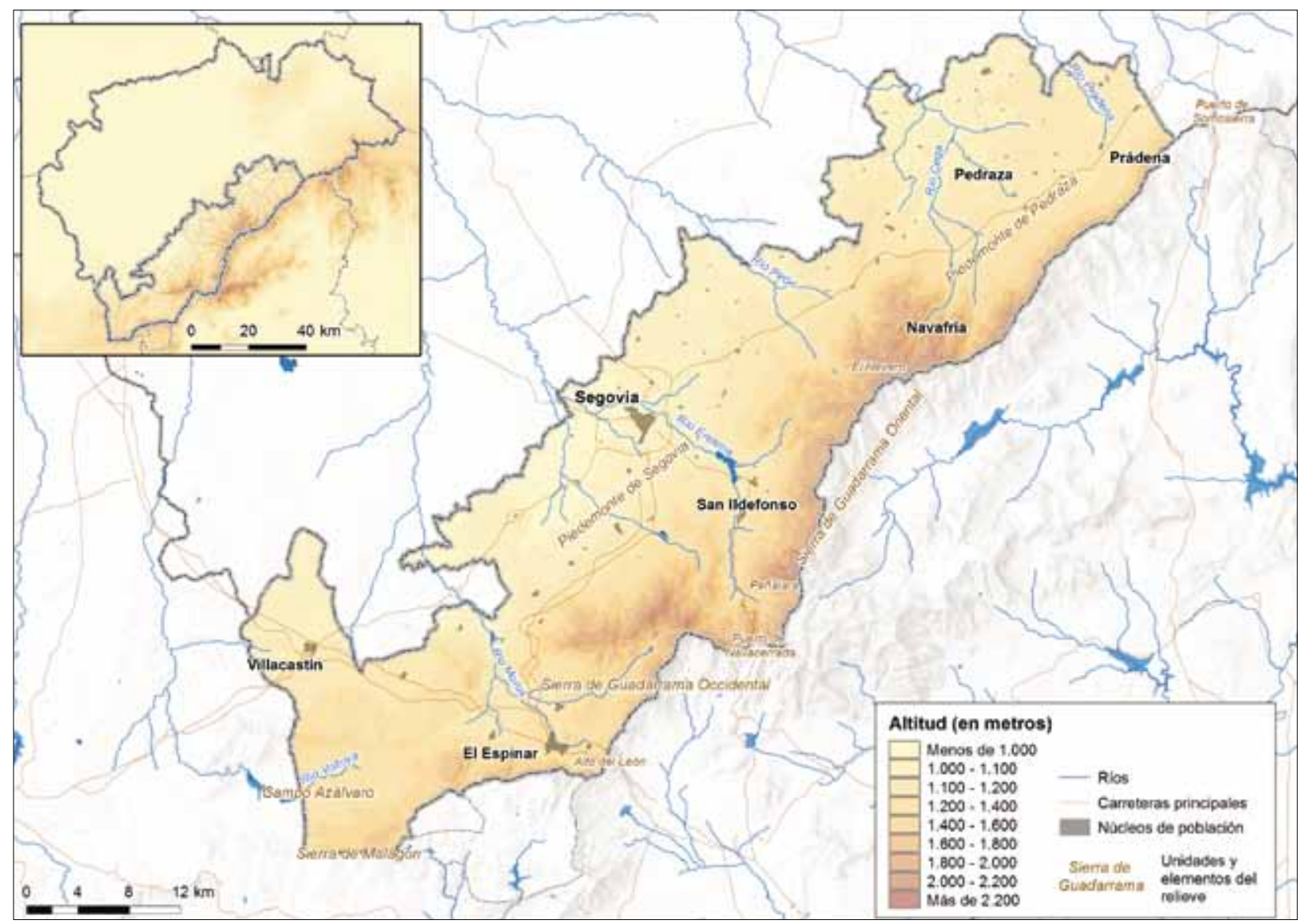

FIG. 1. El Guadarrama segoviano: delimitación y estructura territorial. Elaboración propia.

sido los paisajes «naturales». Responde esta concepción, además, a una tradición naturalista que trasciende a la ciencia geográfica y que tiene raíces muy profundas en la cultura occidental, con lo que la exaltación de los rasgos físicos del espacio constituye un componente esencial de la cultura de nuestro tiempo.

Los últimos decenios de práctica geográfica han supuesto una significativa evolución en las conceptualizaciones del paisaje, y frente al enunciado esencialmente natural del mismo se hace evidente que la propia naturaleza representa un producto de la sociedad. Lo es, ciertamente, como elaboración cultural. Lo es, también, como materialidad alterada, modificada, transformada a lo largo de siglos de actividad humana.

Pero además, este vocablo tan caro a los geógrafos tiende a ser incorporado en los momentos actuales, desde presupuestos eminentemente subjetivistas, como un concepto de raigambre estética, en la medida en que un paisaje conlleva una «composición» sujeta a la posibilidad del disfrute escénico. El paisaje es así comprendido como la dimensión visual del territorio pasada por el filtro de una representación: la cultural.

Y es así, también, como el paisaje interesa por cuanto se erige en una herramienta de suma utilidad pedagógica en el proceso de enseñanza-aprendizaje del territorio, de sus imágenes, en cuanto objetos de estudio geográfico, y de los valores culturales que a ellas se asocian, lo que Ortega y Gasset (1906) denominara de forma expresiva como «la pedagogía del paisaje».

La educación en paisaje está presente en todos los niveles formativos dentro de la enseñanza primaria de nuestro país (Bajo, 2001). Pero el paisaje y su enseñanza, tal y como la planteara Ortega, trasciende por completo el ámbito formal de la escuela para erigirse en instrumento «totalizador» para la acción educativa. Observar e interpretar el paisaje, «saber ver el paisaje», como se suele enfatizar, resulta de interés por cuanto el territorio, sus imágenes y los valores que atesora, constituyen un ámbito de conocimiento, de educación y de ciudadanía (Liceras, 2013). Y es que el paisaje no deja de ser, en 


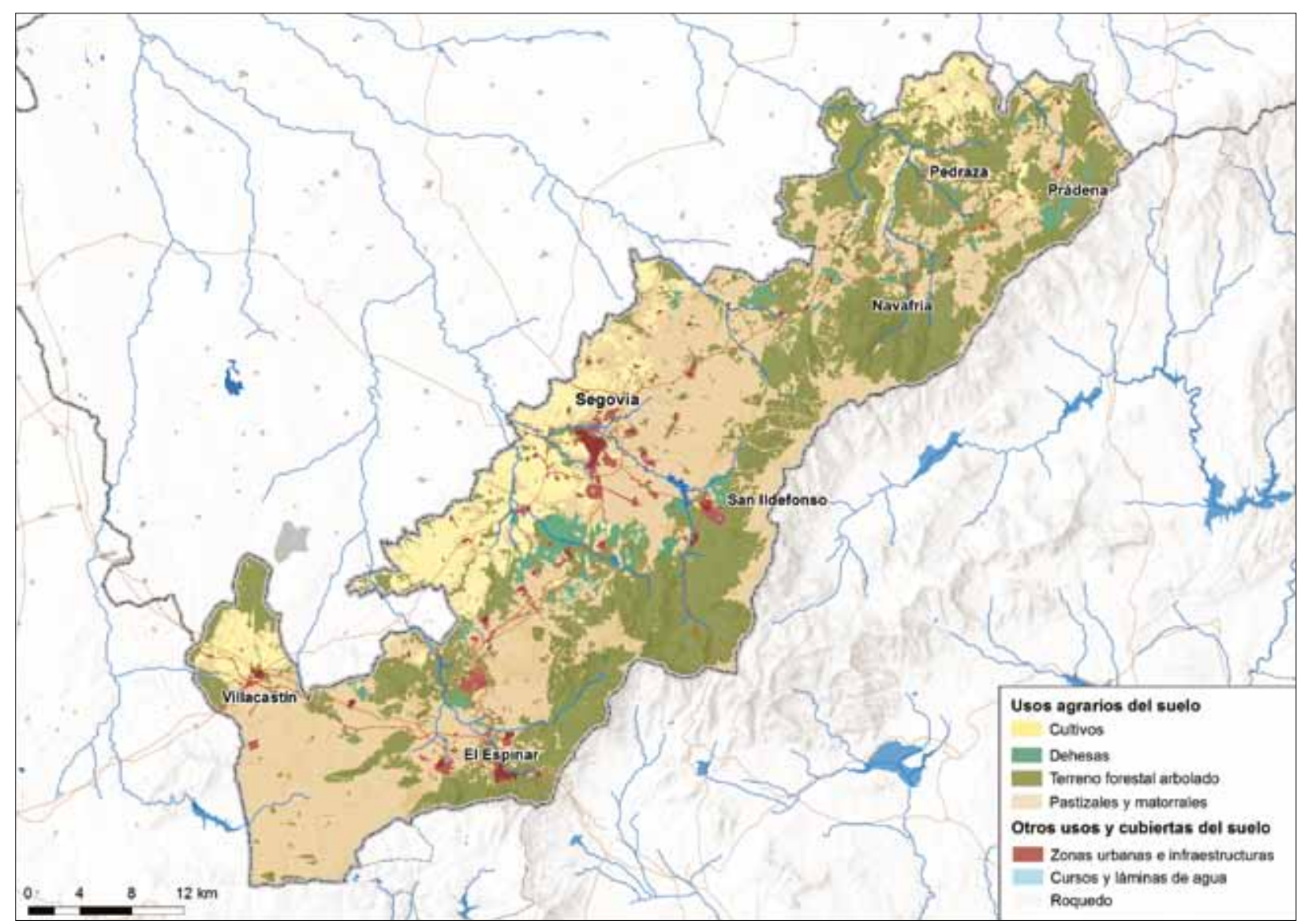

FIG. 2. Usos del suelo en el Guadarrama segoviano. Elaboración propia a partir de IGN y CNIG: SIOSE (Sistema de Información sobre Ocupación del Suelo en España).

esencia, un escenario para el aprendizaje cultural y la sensibilización con el entorno; que es tanto como decir la atención y el cuidado de aquellos espacios considerados como un bien común.

El estudio del paisaje posee, en definitiva, un valor documental y ofrece una utilidad pedagógica a tener muy en cuenta en las programaciones educativas de la enseñanza primaria, al tiempo que posibilita la más que necesaria adquisición de competencias en materia geográfica por parte de los estudiantes universitarios de magisterio. De este interés didáctico deriva, por consiguiente, la atención prestada a los paisajes geográficos de Castilla y León.

\section{MÉTOdo y FUENTES}

El paisaje constituye el objeto de estudio y enseñanza de la geografía. Desde esta premisa inicial, el plantea- miento de una asignatura de contenido geográfico para maestros en el Grado de Educación Primaria de la Universidad de Valladolid (Facultad de Educación de Segovia) descansa en una finalidad esencial: realizar una propuesta didáctica para la interpretación del paisaje que descanse sobre el análisis y la fotointerpretación del territorio castellano y leonés, sentando las bases metodológicas para el estudio de diferentes paisajes geográficos como forma de aprendizaje significativo, a nivel universitario, de los contenidos que sobre el paisaje (como concepto aglutinador de las ciencias sociales y de las ciencias de la naturaleza) marca el currículo de educación primaria en Castilla y León.

¿Cómo abordar la enseñanza-aprendizaje de los contenidos exigidos por el currículo educativo tomando como escenario de aplicación docente el entorno en el que se estudia? o ¿cómo hacer aprehensible, primero a los futuros maestros, para que puedan trasmitir mejor 


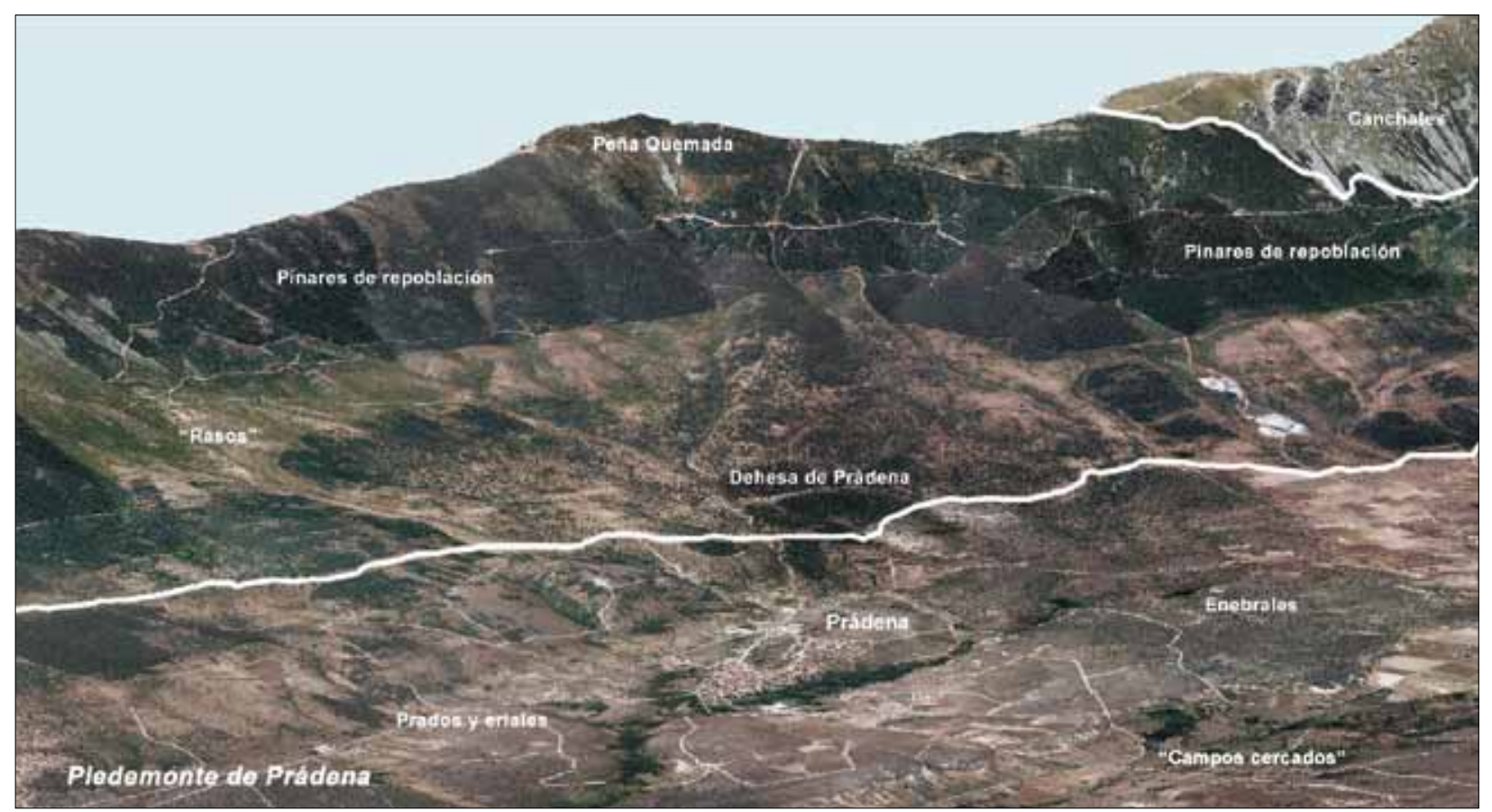

FIG. 3. Recreación tridimensional del paisaje serrano en el entorno de Prádena. Elaboración propia a partir de CIT e ITACyL: Ortofoto PNOA 2014 de Castilla y León. El Guadarrama segoviano es un territorio construido socialmente. Es el producto de un modelo de explotación secular de los recursos que ofrecía el espacio físico: desde las peanas del piedemonte y hasta el «alto de la sierra»; toda una sucesión de ambientes «escalonados» que han destacado históricamente por su importante función como elementos plenamente incorporados al sistema de aprovechamiento ganadero y forestal. Es así como los paisajes serranos, compuestos de herencias diversas y superpuestas, otorgan al territorio su auténtica dimensión cultural. En primer término (en la imagen) el «lugar» de Prádena y sus predios productivos de alrededor: «campos cercados» y campos abiertos que en función del estado de evolución vegetal y del abandono del aprovechamiento ganadero dan lugar a prados y eriales. La Dehesa de Prádena, las «matas» de roble y los enebrales en expansión dando paso a los «rasos» y plantaciones de pinar laderas arriba. Elementos de un segundo «escalón» bajo Peña Quemada, cuyo expresivo nombre da buena cuenta de la evolución seguida históricamente por el espacio forestal. Y por encima de todo, el ambiente cumbreño: huellas del modelado periglaciar, matorrales y pastizales de la «alta sierra».

después a sus alumnos, los valores del paisaje?, son interrogantes fundamentales que pueden ser planteados en los momentos presentes y a los que la orientación dada a la materia Geografía y Sociedad, desde la geografía universitaria, puede servir de respuesta.

El denominado «conocimiento del medio» y su enseñanza práctica en la formación del profesorado de educación primaria no es una cuestión, evidentemente, novedosa (García Ruiz, 2003; Ochaita y Huertas, 1989). Tampoco lo son las propuestas que han venido siendo formuladas sobre la sistematización del conocimiento geográfico a adquirir en los estudios de magisterio (Álvarez, Moraleda y Sanz, 2001; Cascarejo y otros, 2008; Herrero, 1989). En este sentido, la que aquí se contempla es fruto de una experiencia docente e investigadora real, llevada a cabo durante el curso académico 20142015. Esta experiencia ha consistido en la realización de un estudio geográfico conjunto, dirigido por el profesor, tomando en consideración un área concreta dentro del amplio y diverso territorio de Castilla y León. El espacio escogido fue el llamado "Guadarrama segoviano», y en su elección primaron la cercanía y su complejidad, dada la variedad de factores, elementos, procesos y prácticas geográficas que concurren en su configuración. Estos han permitido, por esa misma complejidad, dar un repaso considerable a los contenidos susceptibles de ser considerados como geográficos dentro del desarrollo curricular de las ciencias sociales y de las ciencias de la naturaleza.

El método con el que proceder es el propio del análisis geográfico regional, acomodado en cierta medida a la dimensión didáctico-pedagógica de la experiencia, y que a partir del ejemplo del Guadarrama segoviano puede ser llevada a cabo en cualquier otro ámbito. Esta ha partido de un análisis del territorio, de su definición y delimitación espacial, y de la caracterización de los distintos 
Fig. 4. Evolución del paisaje serrano en el entorno de Prádena.

Fuente: cit e ITACyL: Archivo

de ortofotos históricas (vuelo americano 1956-1957 y vuelo Iryda

1977-1983), ortofoto PNOA 2004 de Castilla y León y ortofoto PNOA

2014 de Castilla y León. En los años cincuenta, el mantenimiento de la población (1.012 habitantes censados en Prádena al comienzo de esa década) obligaba a un aprovechamiento intenso del terrazgo cultivado, cuyo principal fin era la alimentación humana $y$ del ganado en el marco de un sistema agrario de subsistencia.

De ahí la trascendencia que (arriba a la izquierda) adquieren las tierras de labor, ocupando importantes extensiones, tanto en el piedemonte como en la parte más baja de las laderas, y caracterizándose por una excesiva parcelación. Por el contrario,

las masas forestales se veían reducidas, por mor de la dilatada ocupación y utilización histórica

del territorio que había traído consigo la deforestación, con la quema y roturación («rasos») de la mayor parte de la cobertera arbórea («dehesas» $\mathrm{y}$ «matas de robles»).

Así, la porción más sustancial del espacio no cultivado estaba ocupada por prados, generalmente «cercados» y arbolados, que se concentraban en los lugares más aptos del piedemonte y al pie de la Sierra, además de los pastizales de diente ganados a costa del monte y entreverados al matorral en las laderas altas y «cimeras». Al columbrar el decenio de 1980 (arriba a la derecha), el abandono consecuente al éxodo masivo de los años sesenta y setenta (Prádena
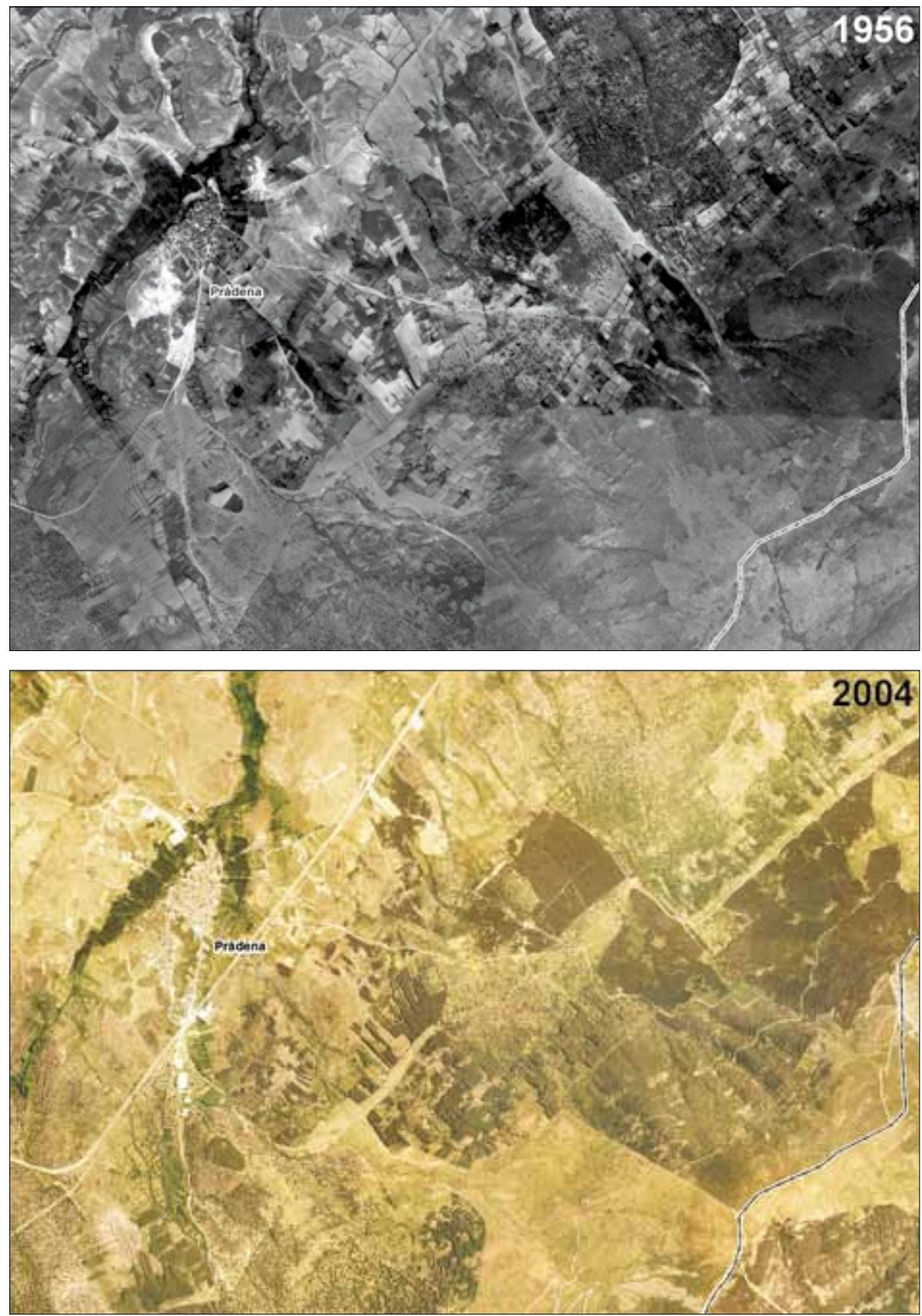

componentes territoriales, a escala municipal, en función de una serie de atributos de orden demográfico, socioeconómico y funcional (posibilitando, con ello, la familiarización con la búsqueda, acceso y manejo de las fuentes estadísticas y documentales al uso). La segunda parte del estudio tiene que ver con la identificación y fotointerpretación de paisajes arquetipo. En su consideración, han sido fijados claramente cuáles son los componentes naturales y sociales de cada paisaje, el tipo de paisaje a partir de los elementos dominantes (alta montaña, media montaña, piedemonte, ciudad, centro comarcal, periferia urbana...) o de las funciones y aprovechamientos que predominan (ganadera, forestal, agraria, terciaria...), el funcionamiento o la dinámica, es decir, los procesos de 

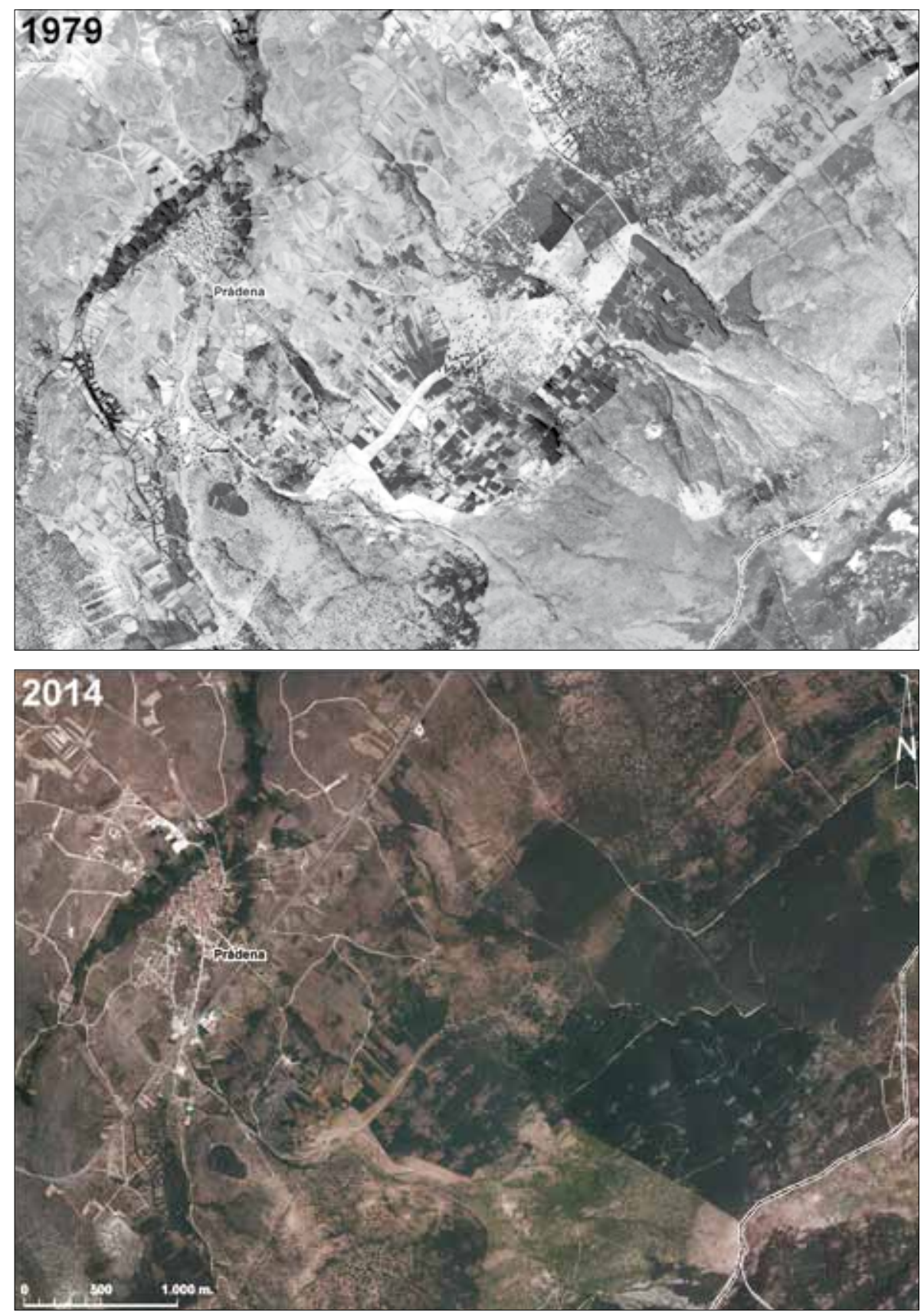

contaba con 518 residentes en 1981 ; cifra que prácticamente mantiene hasta la actualidad) se manifiesta claramente en la reducción de los terrenos agrícolas (localizados, los que se mantienen, en torno al núcleo). Los antiguos campos cultivados se convierten, pues, en eriales y pastizales que son aprovechados de forma extensiva por la ganadería, fundamentalmente, aún en ese momento, lanar (con la trashumancia de radio largo desaparecida por completo desde los años sesenta, el pasado ovino se deja entrever también en la secuencia fotográfica con el nítido trazado de la Cañada de la Vera de la Sierra). Con todo, el avance de la vegetación natural ya es un hecho perfectamente constatable, así como las huellas de los incipientes pinares de repoblación. En el trascurso de los últimos diez años (abajo a izquieda y derecha), la degradación de los usos tradicionales consustanciales al declinar de la dedicación pastoril, hace que esos mismos signos del declive de la tradición constituyan, ya sin remisión, las trazas más expresivas de la (des) organización del paisaje: los «campos cercados» son dejados a merced de la colonización vegetal, que al detalle mostraría igualmente los muros de piedra desparramados sobre el suelo; al tiempo prosigue la enorme expansión de los enebrales, que dominan por doquier sobre las superficies aplanadas de la «rampa»; y, finalmente, las repoblaciones de pinar, algunas tan recientes como lo evidencian las propias terrazas preparadas para la plantación. construcción natural y de transformación social (naturalización, urbanización...) y las distintas valoraciones y sensibilizaciones ambientales y culturales que atesoran y provocan.

Para la explicación de estos paisajes se hace recurrente el empleo de imágenes (Fernández, 2004); y, muy particularmente, la utilización de fotografías aéreas, cu- yas aplicaciones didácticas ya han sido resaltadas en más de una ocasión (García, Martínez y Fernández-Vega, 2015; Fernández, 1990; Valenzuela, 1998). Para ello se ha contado con el enorme caudal documental aportado por el Centro de Información Territorial de la Junta de Castilla y León y el Instituto Tecnológico Agrario de Castilla y León, pudiéndose acceder, desde sus páginas 
web, al archivo y descarga de fotografías aéreas históricas escaneadas y digitalizadas, y a las ortofotos del Plan Nacional de Ortofotografía Aérea. En concreto, para los paisajes arquetipo presentados en este trabajo, han sido usadas fotografías y ortofotografías aéreas correspondientes al vuelo americano 1956-1957, al vuelo Iryda $1977-1983$ y a los PNOA 2004 y 2014.

En definitiva, se da cuenta de una experiencia didáctica a la que va ligada un importante trabajo investigador; también de elaboración formal, redacción y realización esmerada de las representaciones gráficas y cartográficas, que es lo que a continuación se presenta: una memoria final de la asignatura Geografía y Sociedad sobre «Los paisajes del Guadarrama (Segovia)».

\section{EL GUADARRAMA SEGOVIANO: DEFINICIÓN, LÍMITES Y ESTRUCTURA TERRITORIAL}

El territorio objeto de estudio se inscribe, desde el punto de vista de su integración en el espacio físico de la provincia de Segovia, en la vertiente septentrional (o segoviana) del Guadarrama. Esta es, por consiguiente, su malla geográfica de referencia; dando por buena esta nomenclatura para definir a todo el conjunto serrano, a sabiendas de que Guadarrama (topónimo de la localidad, río y puerto homónimos) como buena parte de la vertiente madrileña de esta «Sierra» (antiguos sexmos de Manzanares y de Lozoya) perteneció en tiempos históricos a la comunidad de Ciudad y Tierra de Segovia. Siendo, por tanto, perfectamente válido acuñar el término de «Sierra de Segovia» para una importante porción del ámbito de estudio, si bien otro no menos destacable sector formó parte, igualmente, de la comunidad de Villa y Tierra de Pedraza (y aún de la de Sepúlveda, en sus extremos más orientales). Sea como fuere, el «Guadarrama segoviano», empleando una denominación más propia de cara a los lectores y estudiosos foráneos, se corresponde con la «Sierra», simplemente enunciada, sin epítetos, en el lenguaje común de los habitantes de Segovia.

Entre el puerto de Somosierra (1.444 metros de altitud) y el alto del León $(1.511 \mathrm{~m})$, el Guadarrama se nos aparece por la esbeltez y magnitud del relieve como la Sierra alzaprimada. Comprende, en términos geomorfológicos, una serie de alineaciones montanas que se elevan en ascenso brusco (700-1.000 metros) sobre las rampas de piedemonte al contacto con las llanuras de la Cuenca (piedemontes de Pedraza y Segovia). La línea de debilidad tectónica sobre la que se abre el puerto de Navace- rrada (1.850 metros) es la bisagra de todo este amplio espacio serrano, al dividir en dos a la Sierra: el Guadarrama occidental y el Guadarrama oriental (Bullón, 1988; Sanz, 1988). Y el amplio valle del Lozoya (en Madrid) aparece encuadrado entre las dos ramas principales de esta última porción señalada, correspondiendo la alineada hacia el noreste con los montes Carpetanos propiamente dichos (Fig. 1).

La estructura territorial que descansa sobre la trama geomorfológica apuntada corresponde, en lo administrativo, con 42 términos municipales del borde meridional de la provincia de Segovia (de los 209 con que cuenta ésta); que son los que completa o mayoritariamente participan del espacio físico de la Sierra (o, lo que es lo mismo, sus términos comprenden los volúmenes montañosos del Guadarrama y las peanas de su piedemonte), en un dilatado ámbito de altiplanicies y relieves serranos situado todo él por encima de los 1.000-1.100 metros de altitud ${ }^{5}$. En suma, 1.518,59 kilómetros cuadrados (el 21,9\% del espacio provincial) sirven para encuadrar, finalmente, un territorio que como elementos estructurantes del conjunto cuenta también con una serie de vías de comunicación claves para su vertebración. Unas, las radiales A-1 y A-6/ AP-6/N-VI, que penetran por los márgenes este y oeste, respectivamente, a partir de las grandes aperturas de Somosierra y San Rafael, son las que le otorgan una sobresaliente y decisiva accesibilidad como área de influencia con respecto al exterior. Otras, caso principalmente de la N-603/AP-61, entre San Rafael y Segovia, o la N-110, desde Villacastín al entronque de Santo Tomé del Puerto, las que lo articulan internamente. En cualquier caso, la variedad municipal es la norma, siendo necesario realizar una sucinta caracterización funcional, a esta escala, para poder precisar los diferentes tipos de espacios existentes en función de las dinámicas territoriales que pueden ser identificadas.

La dicotomía territorial es la característica determinante en el Guadarrama segoviano. Un espacio, al oeste, mayormente urbanizado, al compás de los prolongados efectos difusores irradiados desde la metrópoli madri-

\footnotetext{
${ }^{5}$ Quedaría fuera de esta delimitación administrativa el municipio de Santo Tomé del Puerto, cuya porción occidental, a las faldas de Somosierra, la comprendida por las entidades locales de La Rades, Siguero y Sigueruelo, aun pertenenciendo al mismo ámbito serrano, ha sido englobada en otros trabajos de caracterización funcional del Sistema Central segoviano dentro de la Sierra de Ayllón, entendida ésta en sentido amplio (Hortelano, 2012; Plaza y otros, 2008). Una zona delimitada bastante bien ajustada en este sector, por otra parte, con la catalogada como «de montaña» a efectos del cumplimiento de los objetivos de la ley 25/1982, de 30 de junio, de Agricultura de Montaña (BOE, de 10 de julio de 1982)
} 


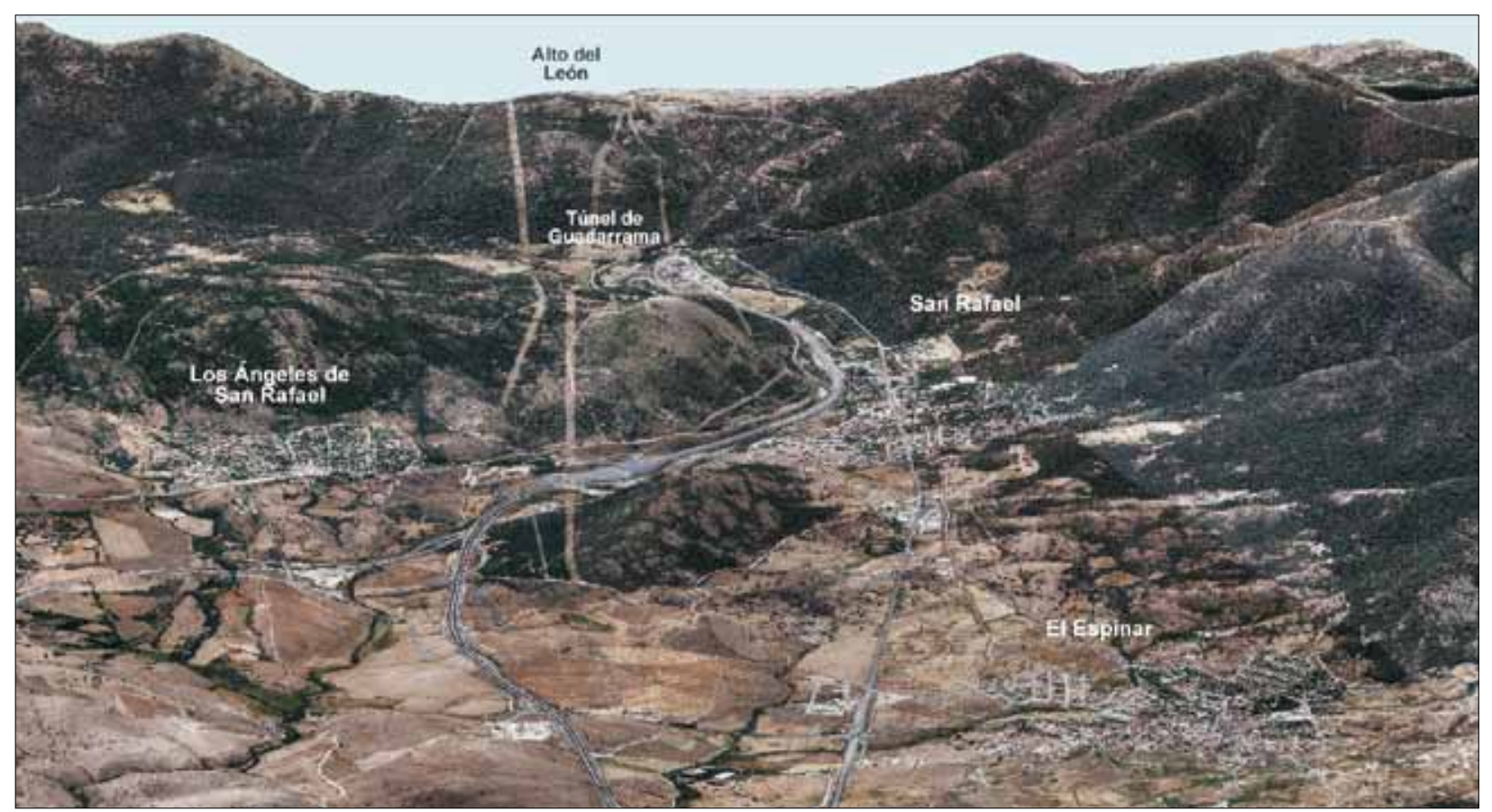

FIG. 5. Recreación tridimensional del paisaje serrano en el entorno de San Rafael-El Espinar. Elaboración propia a partir de CIT e ITACyL: Ortofoto PNOA 2014 de Castilla y León. El alto del León o puerto de Guadarrama $(1.511 \mathrm{~m})$ ha sido, de siempre, el paso más franqueable de entre todos los que comunican las vertientes segoviana y madrileña de la Sierra. Por él discurre, todavía sinuosa, como bien se aprecia en la imagen, la N-VI, la principal vía de comunicación segoviana con la capital de España hasta la entrada en servicio de la AP-6 (el primer túnel, de doble sentido, entró en funcionamento en 1963, el segundo, utilizándose uno en cada sentido, en 1972, y el tercero, reversible en función de las necesidades del tráfico, en 2007). A los pies del puerto, San Rafael ha crecido al compás de la edificación de las «colonias» de vacación estival. Es el segundo núcleo del municipio de El Espinar, nombre dado por la localidad homónima, y ambos se atribuyen, hoy en día, la bicefalia de un centro comarcal de servicios a escala comarcal (servicios educativos, sanitarios, comerciales...), que constituye el municipio más populoso de la provincia de Segovia tras su capital (9.654 habitantes en 2014). La urbanización de Los Ángeles de San Rafael, levantada sobre la antigua finca de El Carrascal, un topónimo bien expresivo de lo que esos pagos eran con anterioridad, a partir del Plan Parcial de 1967, fue el primer ejemplo de espacio residencial de creación ex novo vinculado al recreo estacional madrileño en el Guadarrama segoviano.

leña, que aparece articulado territorialmente por los centros de servicios de primer orden de El Espinar (con los núcleos principales del propio El Espinar y de San Rafael) y San Ildefonso o La Granja, y por el área urbana de Segovia, configurada por la propia capital y los municipios de su entorno. Unos, los calificados como periurbanos en sentido estricto, que son los que durante más tiempo e intensidad han venido recibiendo los estímulos provenientes de la ciudad. Otros, nombrados, en sentido amplio, como de área de influencia, son los que más recientemente, desde la década de 2000, o antes pero con menor intensidad recibieron esos mismos influjos, traducidos siempre en un trasvase de población (de actividades en cierta manera también desde la ciudad). Con todo, se trata de un área definida en su momento como de «fuerte dinámica de cambio» provocada por la irrupción masiva de nuevas funciones (la turística y la residencial, por encima del resto $)^{6}$. Al este de la pequeña aglomeración segoviana, el espacio serrano se resuelve, y hasta el área de dominancia comarcal de Riaza y de los impulsos exógenos que penetran por la escotadura de Somosierra (municipios de Santo Tomé del Puerto, Cerezo de Arriba o Cerezo de Abajo), en una suerte de zona fuertemente ruralizada y lábilmente poblada. Un territorio «regresivo en situación crítica», se decía en ese mismo trabajo ci-

\footnotetext{
${ }^{6}$ Una aproximación al ámbito tratado, definiendo con las palabras entrecomilladas la dinámica territorial de los diferentes sectores, dentro de estudios más amplios circunscritos a todo el Sistema Central castellano y leonés, aparece en Díez (2003) y Troitiño (1990). Acerca de la importancia transformadora de la urbanización y su incidencia espacial en el Sistema Central puede verse Plaza y otros (2010). Sobre la influencia metropolitana de Madrid son interesantes las aportaciones llevadas a cabo por Solís (2008 y 2011), así como las de Velasco (2011) con respecto a los cambios territoriales experimentados en el entorno periurbano por mor de la expansión urbanística de Segovia.
} 
FIG. 6. Evolución del paisaje serrano en el entorno de Revenga,

Navas de Riofrío, La Losa y

Ortigosa del Monte. Fuente: CIT e ITACyL: Archivo de ortofotos históricas (vuelo americano 19561957 y vuelo Iryda 1977-1983), ortofoto PNOA 2004 de Castilla y León y ortofoto PNOA 2014 de Castilla y León. La N-603, desde San Rafael a Segovia, y más recientemente, paralela a la anterior, la AP-61 (inaugurada en 2004), son las infraestructuras viarias que sirven de soporte y de explicación, en parte, al «corredor» urbanizado que, a partir de los núcleos de Ortigosa del Monte, La Losa y Navas de Riofrío (Revenga es una entidad local menor perteneciente al municipio de Segovia), ligan el piedemonte del Guadarrama occidental con la «invasión» espacial madrileña (en menor medida como espacios de ocio y residencia segoviana, en un primer momento). Todavía en los años cincuenta (arriba a la izquierda), e incluso a finales de los setenta y comienzos de los ochenta (arriba a la derecha), la organización del espacio era la tradicional. «Campos cercados»,
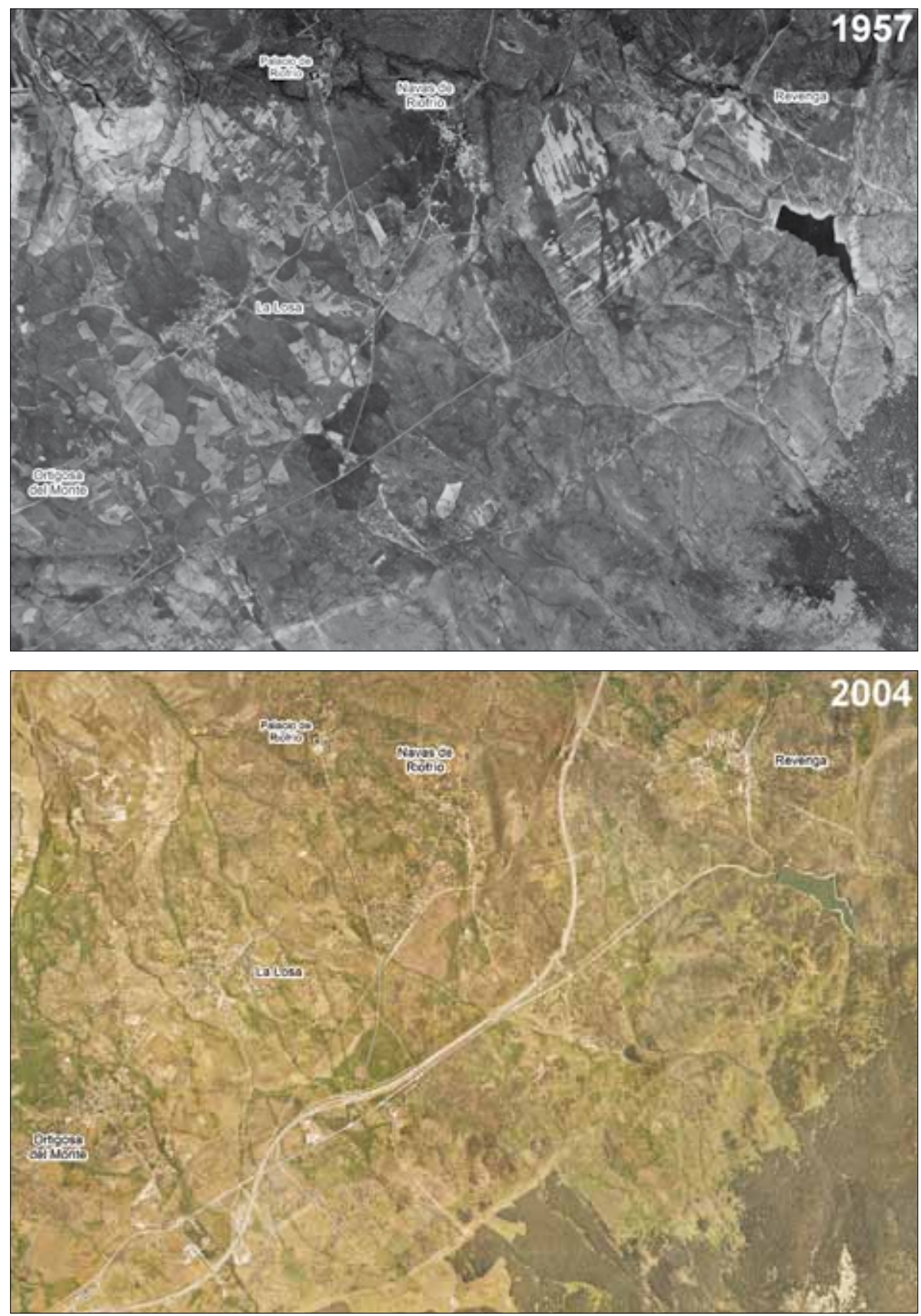

tado al pie para 1990, un área «regresiva con los sectores tradicionales en crisis y una presencia creciente de actividades transformadoras», en el mencionado para 2003; diagnóstico más cercano con la aproximación efectuada en estas páginas.

Administrativamente, esta porción oriental es un espacio fragmentado en pequeños municipios dotados de un nivel de equipamientos y de servicios básicos muy elemental, muchos de ellos apenas cuentan con el consultorio médico rural, que no atiende todos los días, y carecen de cualquier tipo de establecimiento de alimentación. Es un territorio que históricamente fue articulado por «villas» ajenas o pertenecientes al ámbito serrano (Sepúlveda o Turégano, entre las primeras; Pe- 

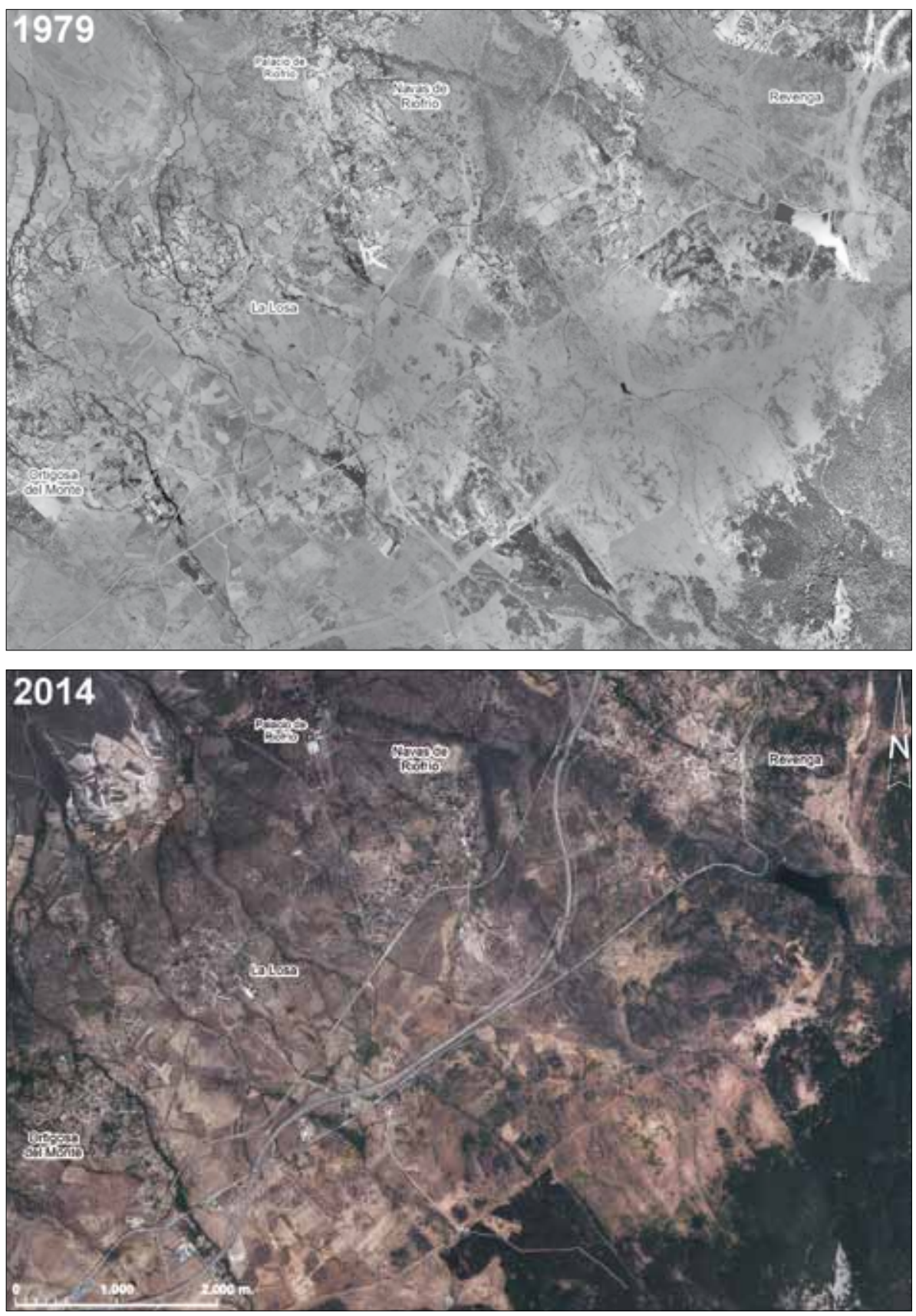

«dehesas», «matas» de robles y encinas eran lo sustancial de los predios que rodeaban los pueblos. Estos constituían, aún, un típico modelo de poblamiento rural concentrado de carácter polinuclear, en base al compacto casalicio con calles. Los años ochenta y, sobre todo, los noventa y hasta el momento actual, han representado la transformación del paisaje en estos ámbitos de la peana serrana (abajo a izquierda y derecha). Las urbanizaciones de nueva creación, los sensibles aumentos del espacio edificado de los núcleos, el auge de las segundas residencias, en suma, marcan el signo de los tiempos cambiantes. Como evidencia de una función recreativa secular y de valorización de un territorio singularizado por su riqueza ambiental, el Palacio de Riofrío es fiel testigo de todo este proceso. Desde los años noventa, además, estos tres municipios (que han visto crecer sus vencidarios) comienzan a recibir los estimulos de la influencia urbana de la ciudad de Segovia, pasando a incorporarse al área urbana de la capital, en un paralelo proceso de periurbanización. draza y Prádena entre las segundas). Son estas últimas, precisamente, las que continúan canalizando lánguidamente la prestación de servicios esenciales a sus contornos rurales de referencia, si bien en una posición que nada tiene que ver con su importancia pasada, como lo denotan sus menguados vecindarios (426 y 567 habitantes, respectivamente, en 2014). No en vano, ninguna de ellas es siquiera considerada como centro de servicios de tercer nivel (el más bajo de todos) en las diferentes clasificaciones y tipologías municipales establecidas a tal efecto (Gil, 2012; Molina y Delgado, 2014). Aunque Prádena, que cuenta con un centro de educación obligatoria (educación infantil, primaria y secundaria obligatoria), servicios bancarios, comerciales y farmacia (y 
a pesar de que el centro de salud ubicado en el área de estudio se encuentre en Navafría), pudiera ser, a esta escala de análisis, conceptuado como centro comarcal de esa categoría.

Algo parecido podría ocurrir con Villacastín, en el margen occidental, que con más motivo aún, por talla demográfica (1.542 habitantes en 2014) y por albergar centro de salud y centro de enseñanza obligatoria, además de múltiples servicios bancarios, comerciales y farmacéuticos, sería catalogado como tal. Postergado en las clasificaciones al uso al estar inmerso en un ámbito comarcal capitalizado por El Espinar-San Rafael, provisores de servicios de primer nivel (centro de salud, colegios de educación infantil y primaria, instituto de enseñanza secundaria obligatoria y bachillerato).

En esencia, a la concentración de población, actividad y dotación de servicios más especializados del ámbito serrano más urbanizado (que se continuaría por La Granja y el área periurbana y de influencia urbana de Segovia) se contrapone la Sierra calificada por algunos estudiosos como «elusiva», la que permanece eludiendo sin dejar de estar incorporada del todo a los efectos más dinamizadores de la «invasión» espacial llegada desde allende sus límites. Y es a estos sectores, en definitiva, a los que corresponden los paisajes elegidos para su explicación, los paisajes arquetipo del Guadarrama segoviano.

\section{LOS PAISAJES SERRANOS: LAFOTOINTERPRETACIÓN DE PAISAJES ARQUETIPO}

\section{NATURALEZA, «CAMPO» Y ESPACIO URBANIZADO: \\ EL MOSAICO DE USOS DEL SUELO Y LA DIFERENCIACIÓN DE UNIDADES DE PAISAJE}

En la Sierra de Guadarrama (Segovia), las áreas forestales, entendidas en sentido restringido como el terreno forestal arbolado, representan la proporción mayoritaria de la superficie comprendida por los 42 municipios que componen el conjunto territorial. La preponderancia de los paisajes boscosos continúa siendo el principal escenario visual del espacio serrano: el arquetipo fundamental de su organización. Algo menor, a tenor de los datos proporcionados por el SIOSE, es el predicamento y significado que tienen las zonas contempladas como de prados, pastos y matorral. Son el cortejo idóneo, sin olvidar la mixtura con la que igualmente aparecen en conjunción con el dominio del árbol, para la explotación ganadera, desde las «cimeras» de los bloques erguidos y hasta las plataformas de piedemonte, donde la naturaleza de los suelos labrados sobre los materiales del zócalo y su orla de cobertera restringe casi por completo la vocación agrícola. Unas tierras de cultivo que, representadas por un exiguo terrazgo de secano, aparecen confinadas a los sectores más bonancibles, los de un mayor desarrollo edáfico y una menor altitud (empero una menor irrigación que restringe el uso pratense), a merced de la labor incisiva de los cursos fluviales sobre el pedimento o a una favorecida inclinación de este, en los mismos márgenes del ámbito serrano. Finalmente, las «dehesas» y los terrenos adehesados son la manifestación última del paisaje de las peanas, con los montes ahuecados de quercíneas como máxima expresión (Fig. 2).

Y es así como encinares, rebollares, sabinares y pinares montanos, por mor de unas condiciones climáticas y de unos suelos de naturaleza cambiante, además, y, por encima de cualquier otra consideración, de una contumaz intervención del hombre, se acaban conformando como las facies predominantes de la floresta arbórea, de cariz eminentemente mediterránea. Unas vestes forestales que, de consuno con pastizales y matorrales, prosiguen marcando las que han sido las dedicaciones productivas por excelencia: la explotación forestal y, de manera decidida, con base también en el extenso ambiente de montes y pinares, el aprovechamiento ganadero.

Al él obedece todavía, como no podía ser de otra manera, el mantenimiento de los usos agrarios del suelo. Se continúa haciendo explícita así la vocación pastoril de esta comarca serrana. Pastos montanos y matorrales subalpinos, sotobosques de hierbas y arbustos bajo el dosel de las masas arbóreas, matorrales de degradación o sustitución, prados y praderías no sin las limitaciones de un clima donde la aridez reduce la producción y seca el fino herbazal durante el estío, han servido de asiento y acomodo para una importante cabaña pecuaria; con las explotaciones más boyantes orientadas fundamentalmente, a día de hoy, al bovino de carne en régimen extensivo, con las vacas de cría y novillas constituyendo la base generatriz de la producción de terneros. Sin dejar de ser abultados, en cuantía numérica los más, los hatos de ovejas, el ganado ovino que tanta fama y predicamento otorgó en el pasado a estos pagos.

Sea como fuere, y aunque los signos del abandono y de la degradación de la actividad ganadera tradicional son evidentes por doquier, la imbricación de estos tipos de esquilmos con la organización del espacio se mantiene clara. Y ello a pesar de que los predios cultivados rompan, mayormente, con lo que eran los labrantíos de antaño: las tierras de pan llevar y el policultivo de 


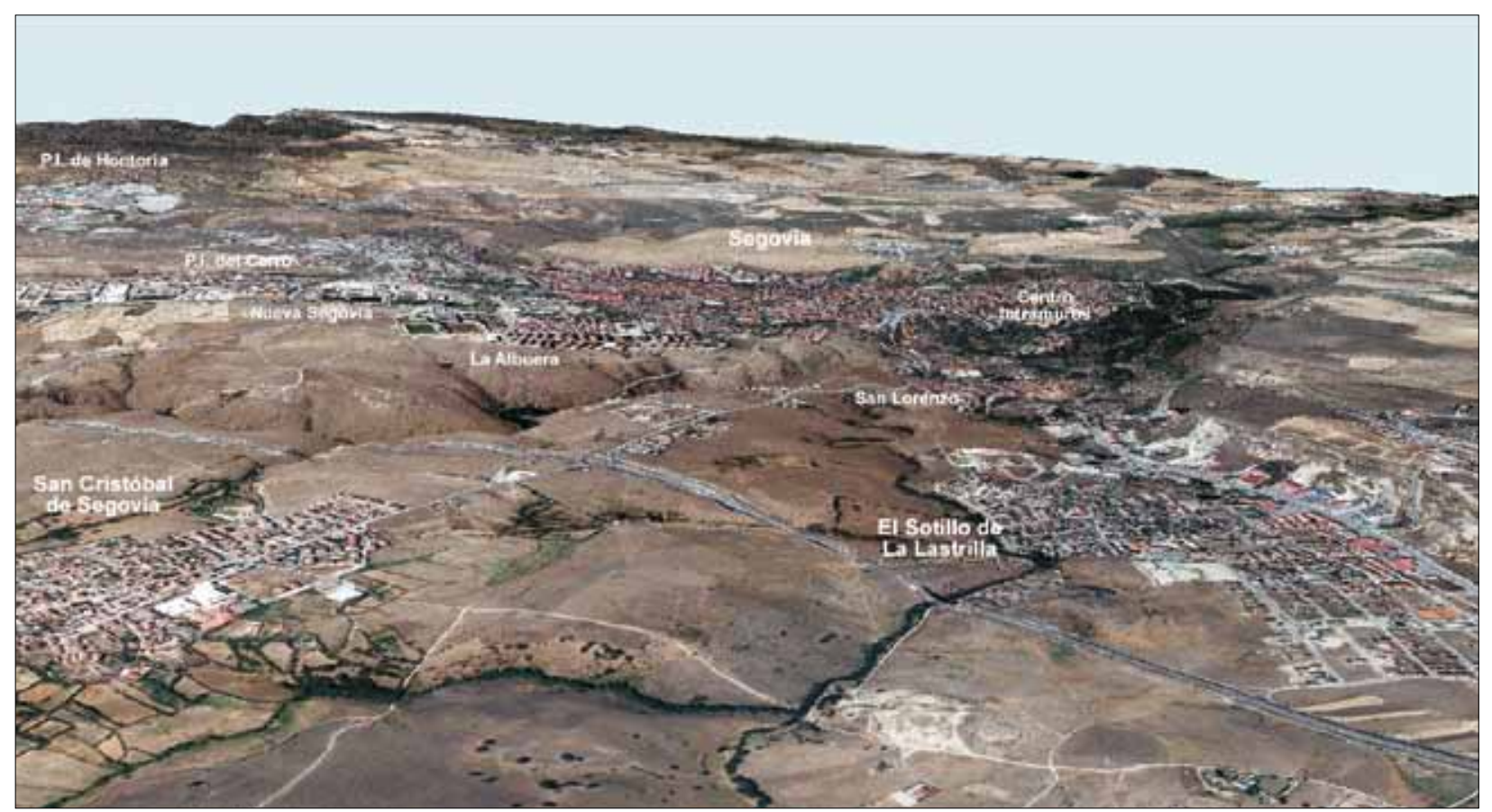

FIG. 7. Recreación tridimensional del paisaje en el entorno de la ciudad de Segovia. Elaboración propia a partir de CIT e ITACyL: Ortofoto PNOA 2014 de Castilla y León. En el margen de las campiñas sedimentarias de la cuenca del Duero y como antesala de los rebordes montañosos paleozoicos del Guadarrama, la ciudad de Segovia y su entorno se inscribe en un espacio de transición. Una estrecha franja entre las llanuras mayoritariamente arcillosas y de aptitud eminentemente cerealista y el horst granítico-gnéisico de la alineación serrana meridional, de vocación más forestal y pratense. Una trama natural que ha condicionado y condiciona la ubicación y el desarrollo fragmentado del área urbana segoviana, sobre un afloramiento parcial de la orla calcárea mesozoica (que en superficie da lugar a las aplanadas lastras), bien incidido por la red fluvial del Eresma-Clamores.

subsistencia comunes a la inmensa mayoría de las áreas montanas del país. Apenas quedan tierras que cultivar, si bien nunca fueron lo sustancial de la utilización del territorio, mas todo lo contrario. Con todo, son producciones agrícolas que se supeditan, sobremanera, como destino a la alimentación y engorde animal (piensos compuestos y forrajes), a esa otra dedicación ganadera que menos tiene que ver con la de corte tradicional, la de tinte estabulada e industrial, manifestada en el vacuno de leche y en las piaras porcinas. Lo que no es óbice, en definitiva, para que la parte más sustancial del mosaico actual de los usos del suelo deje de tener que ver con las que han sido las claves históricas de la organización del territorio.

La contraparte tiene que ver con las enredadas funciones y formas de lo urbano, con la ciudad de Segovia y su radio de influencia periurbana, con los núcleos de San Rafael-El Espinar y La Granja y sus áreas intersticiales más o menos coaligadas de carácter urbanizado, con crecimientos residenciales y equipacionales «desparramados» por el territorio. Y es así como de un fondo de trazos eminentemente rurales, que imprimen un marcado cariz al conjunto, emergen estos elementos añadidos producto de la transformación. En suma, el espacio urbanizado, al socaire de los más novedosos procesos de concentración y difusión irradiados desde allende la Sierra o desde la capital provincial, más recientemente, el «campo» y la naturaleza, progresivamente omnipresente según se avanza hacia los bordes serranos más inaccesibles, marcan las coordenadas morfológicas de la tesela de usos del suelo, así como los atributos dominantes de las distintas unidades de paisaje identificadas, por ser las imágenes del territorio más representativas.

\section{El GuAdarRama SEgOVIANO ORIENTAL:} «ABANDONO» Y HERENCIAS DEL PAISAJE TRADICIONAL

\section{A) Localización y rasgos distintivos de la unidad}

La primera de las unidades diferenciadas se inscribe en el espacio físico comprendido por los piedemontes de 
FIG. 8. Evolución del paisaje en el área urbana de Segovia. Fuente: CIT e ITACyL: Archivo de ortofotos

históricas (vuelo americano 1956-1957 y vuelo Iryda 1977.

1983), ortofoto PNOA 2004 de

Castilla y León y ortofoto PNOA 2014 de Castilla y León. Sobre los condicionantes naturales de lastras, escarpes y vaguadas, de cuestas y desniveles, es como se ha ido construyendo históricamente la ciudad y su área de influencia. La sociedad segoviana en su devenir temporal ha ido produciendo un espacio urbano cuya estructura actual aparece definida a partir de un «centro», que puede ser identificado con la ciudad histórica. En ella se diferenciaban claramente una serie de espacios más o menos contiguos: el centrointramuros, verdadero elemento primigenio dentro del recinto amurallado, el centro-extramuros, en continuidad al anterior, evidenciando la primera expansión (burguesa) superficial de la ciudad,

y los arrabales tradicionales de

San Millán y San Lorenzo. Esta configuración, que se mantuvo a lo largo del tiempo, sufrió una gran transformación desde el momento en el que la ciudad comenzó

a experimentar un incremento sustancial de población, a partir del segundo tercio del siglo $\mathrm{xx}$
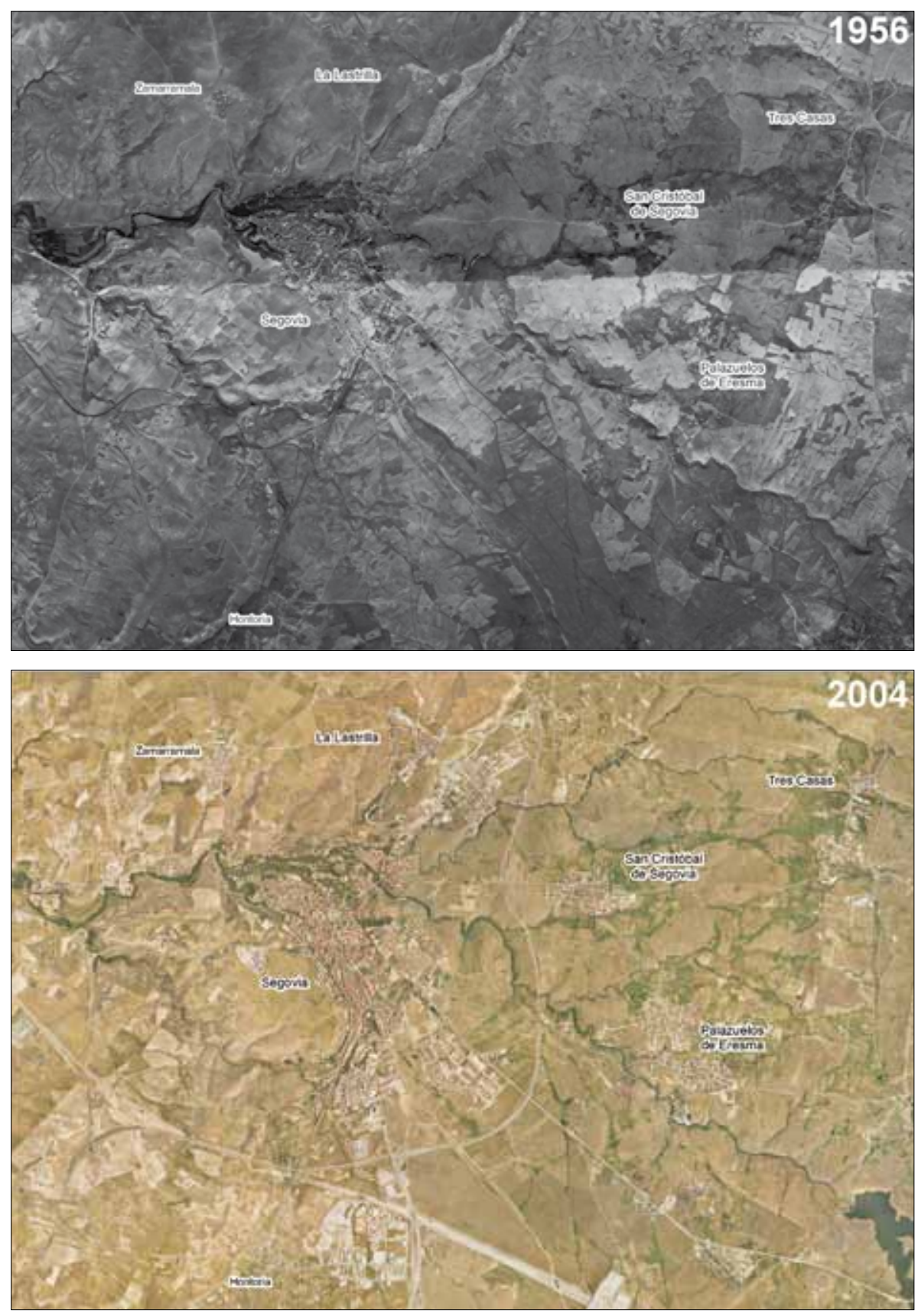

Pedraza y Segovia y el Guadarrama oriental propiamente dicho (los montes Carpetanos). Se trata de un territorio que, desde el punto de vista funcional, ha sido definido como «regresivo» en términos de comportamiento demográfico y dinámica socioeconómica (Troitiño, 1990, p. 117), con el sector agrario en crisis y una cierta readaptación en forma de «presencia creciente» de nuevas ac- tividades, en particular las de índole turístico-residencial (Díez, 2003, p. 744).

\section{B) Organización y evolución del paisaje}

El aprovechamiento ganadero es el factor dominante de la organización del espacio. Si bien, desde la década 

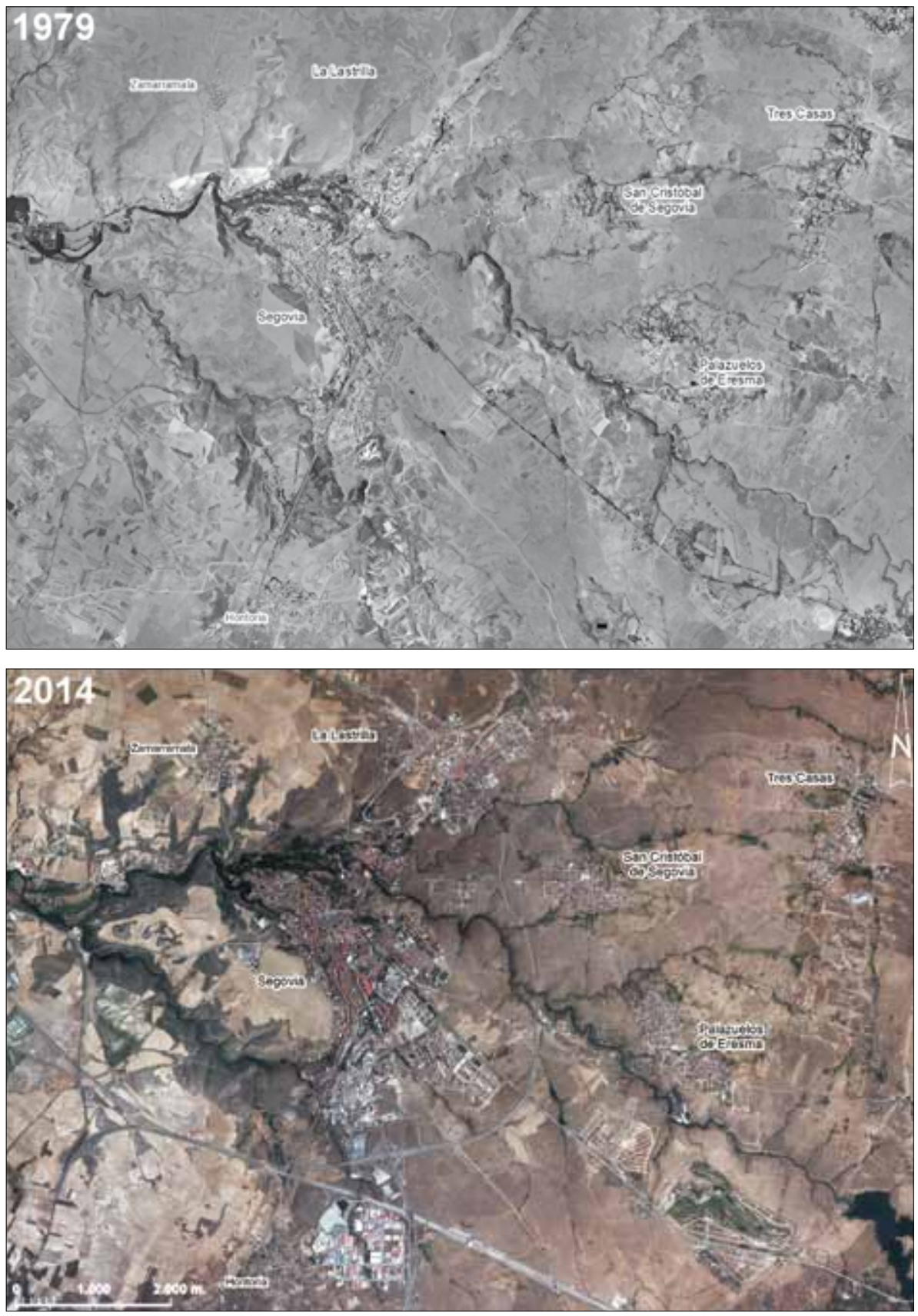

(arriba a la izquierda). Fue entonces cuando comenzaron las ocupaciones progresivas y la edificación de nuevos terrenos, cada vez más alejados, destinados a satisfacer la creciente demanda residencial. Barrios como los de la Albuera, Estación, San JoséMirasierra y Cristo del Mercado fueron surgiendo y desarrollándose al compás del continuado aumento poblacional de la ciudad (arriba a la derecha). Más recientemente, el moderno polígono residencial de Nueva Segovia y las recentísimas y en edificación promociones de la Comunidad de Ciudad y Tierra de Segovia se han acabado consolidando como los nuevos espacios residenciales de la capital (abajo a izquierda y derecha). Unos crecimientos urbanos periféricos que comienzan a manifestarse más allá de los límites de la ciudad, alcanzando a varios núcleos de su entorno más inmediato. Así son cada vez más sensibles los trasvases de población hacia algunos de los denominados «barrios incorporados» (Hontoria y Zamarramala, en las imágenes) o a municipios circundantes como los de La Lastrilla, San Cristóbal de Segovia, Palazuelos de Eresma o Tres Casas, y que hasta los años 1990 y 2000 apenas conocieron el cambio urbanístico y funcional. de 1950, la actividad pecuaria empieza a entrar en un declive prolongado, reduciéndose el número de explotaciones y la cuantía de cabezas de ganado. Un abandono de las prácticas pastoriles que se evidencia, igualmente, en la inexorable tendencia hacia la simplificación en el manejo de los animales y la utilización selectiva del suelo. Sucede, de este modo, la crisis del sistema tra- dicional y del modelo territorial en el que este se apoyaba, progresivamente sustituido por una organización geográfica de corte tradicional-degradado. Su correlato se encuentra en el prolongado proceso de despoblación acontecido desde entonces, como las sensibles mermas de población registradas, las perceptibles modificaciones habidas en el tamaño y número de asentamientos o el 
excesivo grado de envejecimiento terminan por demostrar (Figs. 3 y 4 ).

\section{El Guadarrama segoviano centro-occidental: «INVASIÓN» FORÁNEA Y TRANSFORMACIÓN DEL PAISAJE}

\section{A) Localización y rasgos distintivos de la unidad}

La segunda de las unidades diferenciadas se inscribe en el espacio físico comprendido por los piedemontes de Segovia y Villacastín y el Guadarrama centro-oriental y occidental. Se trata de un territorio que, desde el punto de vista funcional, ha sido definido como de «fuerte dinámica de cambio» (Troitiño, 1990,p. 131), con el sector agrario en crisis y «una intensa dinámica de transformación provocada por la irrupción masiva de nuevas actividades de carácter recreativo y el auge de las residencias secundarias» (Díez, 2003, p. 754).

\section{B) Organización y evolución del paisaje}

La intensa producción de espacios urbanizados y de ocio vinculados a la aglomeración madrileña es el proceso dominante de la construcción actual del espacio serrano al oeste del área urbana de Segovia. La extraordinaria accesibilidad espacial, por mor de la entrada en funcionamiento de los túneles de Guadarrama (que datan de 1963, 1972 y 2007) se erige como el principal factor explicativo del fenómeno de «invasión» foránea que caracteriza al «corredor»San Rafael-El Espinar-Segovia. Es así como los núcleos de poblamiento tradicional y algunos otros centros vacacionales de raigambre histórica, caso de La Granja, han visto aumentar considerablemente sus espacios residenciales, al tiempo que los antiguos paisajes agroganaderos de «campos cercados», «dehesas»y abertales han dado paso a la ubicación de nuevos equipamientos e instalaciones ligadas al turismo y al recreo estacional, pero también a una población local que no cesa de crecer, bien es cierto que por lo anterior (Figs. 5 y 6).

\section{La ciudad de Segovia y su entorno Serrano: EL PAISAJE PERIURBANO}

Sobre el espacio físico del piedemonte segoviano, la ciudad de Segovia ha venido consolidando un importante área de crecimiento residencial que desborda hacia el municipio periurbano de La Lastrilla y otros veintidós términos calificados como de influencia urbana, trece de los cuales están localizados, estrictamente, dentro del ámbito considerado como Sierra de Guadarrama. La renovación urbana y las nuevas formas de crecimiento residencial son los atributos más remarcados de este territorio, sobre los que se fundamenta «la consolidación de un área urbana de tamaño intermedio en el entorno de la capital» (Molina y Delgado, 2014, p. 361) (Figs. 7 y 8).

\section{CONSIDERACIONES FINALES}

El análisis territorial y la fotointerpretación del paisaje de la Sierra de Guadarrama (Segovia) es el hilo conductor de la experiencia docente e investigadora que, enmarcada en la asignatura Geografía y Sociedad, de cuarto curso del Grado de Educación Primaria por la Universidad de Valladolid (Facultad de Educación de Segovia), ha sido llevada a cabo a lo largo del año académico 20142015. Su concreción formal es la memoria que bajo el título Los paisajes del Guadarrama (Segovia) se presenta como la parte sustancial de este artículo.

Partiendo de la premisa inicial de que es necesario conocer para poder enseñar, el desarrollo de la experiencia no ha hecho sino cumplir con la finalidad con la que fue concebida: proporcionar a los futuros maestros las claves explicativas para la comprensión de los elementos y procesos geográficos, de cara a facilitar la adquisición de unas competencias que se creen elementales para su formación académica y posterior ejercicio profesional. En suma, realizar una propuesta didáctica para la interpretación del paisaje que descanse sobre el análisis y la fotointerpretación del territorio, sentando las bases metodológicas para el estudio de diferentes paisajes geográficos como forma de aprendizaje significativo, a nivel universitario, de los contenidos que sobre el paisaje (como concepto aglutinador de las ciencias sociales y de las ciencias de la naturaleza) marca el currículo de educación primaria en Castilla y León.

El método con el que proceder es el propio del análisis geográfico regional, acomodado a la dimensión didáctico-pedagógica de la práctica investigadora. Ésta ha partido de un análisis del territorio, de su definición y delimitación espacial, y de la caracterización de los distintos componentes territoriales, a escala municipal, en función de una serie de características demográficas, socioeconómicas y funcionales. Y ha continuado con la identificación e interpretación, a partir de la utilización de fotografías y ortofotografías aéreas, de los paisajes arquetipo del Guadarrama segoviano: los paisajes tradi- 
cionales, los paisajes urbanizados y los paisajes periurbanos.

En definitiva, el trabajo presentado da respuesta a un interrogante fundamental que pueden ser planteado en el momento presente: ¿cómo abordar la enseñanza-aprendizaje de los contenidos geográficos exigidos a un maestro tomando como escenario de aplicación docente el propio entorno en que se estudia? Y aún en sentido más amplio resolver una segunda cuestión que subyace a todo este artículo y lo trasciende: ¿cómo establecer los lazos entre la geografía que se ha de practicar en la escuela y la geografía que se cultiva en la universidad?

\section{BIBLIOGRAFÍA}

Álvarez Orellana, M. ${ }^{a}$ F., C. Moraleda Nieto y M. ${ }^{a}$ G. SANZ SANJosé (2001): «Propuesta para la sistematización del conocimiento geográfico en la formación

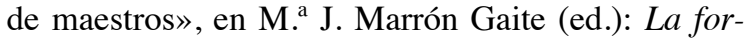
mación geográfica de los ciudadanos en el cambio de milenio. Grupo de Didáctica de la Geografía de la Asociación de Geógrafos Españoles y Departamento de Didáctica de las Ciencias Sociales de la Universidad Complutense de Madrid, Madrid, pp. 281-294.

B AJo BAJo, M. ${ }^{a}$ J. (2001): «El paisaje en el curriculum de educación primaria, dentro del área de conocimiento del medio natural, social y cultural». Aula, núm. 13, pp. 51-61.

Bullón Mata, T. (1988): El sector occidental de la Sierra de Guadarrama. Trama geomorfológica de un paisaje montañoso. Comunidad de Madrid, Madrid, $283 \mathrm{pp}$.

Cascarejo Garcés, A., J. J. Díaz Matarranz, J. A. Díaz Serrano, M. ${ }^{a}$ C. Carretero Albiñana y M. García ESTRADA (2008): «La formación geográfica del maestro». Serie Geográfica, núm. 14, pp. 17-30.

Díez Mayoral, D. (2003): Políticas de intervención y dinámicas territoriales en las áreas del Sistema Central de Castilla y León. Tesis doctoral, Universidad Complutense de Madrid, Madrid, 896 pp.

Fernández García, F. (2004): «La explicación del paisaje a través de la imagen». Ería, núm. 63,pp. 117-119.

Fernández Martínez, M. ${ }^{a}$ V. (1990): «La fotografía aérea: usos y manejo con fines didácticos». Tabanque, núm. 6, pp. 51-64.

García de Celis, A. J., L. C. Martínez Fernández y B. Fernández-Vega Peláez (2015): Los paisajes glaciares de Fornela (León). Docencia, investigación y divulgación del patrimonio natural de la Reserva de la Biosfera de los Ancares Leoneses. Universidad de Valladolid, Valladolid, $186 \mathrm{pp}$.

García Ruz, A. L. (2003): El conocimiento del medio y su enseñanza práctica en la formación del profesorado de educación primaria. Natívola, Granada, 138 pp.

Gil Álvarez, E. (2012): «Los centros comarcales de servicios en las sierras meridionales de Ávila y Segovia: tipología y caracterización demográfica y productiva», en O. de Cos Guerra y P. Requés Velasco (coords.): La población en clave territorial: procesos, estructuras y perspectivas de análisis. Actas del XIII Congreso de la Población Española. Ministerio de Economía y Competitividad/Asociación de Geógrafos Españoles/Universidad de Cantabria, Santander, pp. 257-267.

Herrero Fabregat, C. (1989): «La didáctica de la geografía en las escuelas universitarias de magisterio». Boletín de la Asociación de Geógrafos Españoles, núm. 8, pp. 81-91.

Hortelano Mínguez, L.A. (2012): «Las mudanzas y readaptaciones de la Sierra de Ayllón: la gestión sostenible del territorio y el fomento de las actividades turísticas», en C. Delgado Viñas y J. I. Plaza Gutiérrez (eds.): Territorio y paisaje en las montañas españoles. Estructuras y dinámicas espaciales. Ministerio de Ciencia e Innovación/Librería Estvdio, Santander, pp. 109-119.

Liceras, A. (2013). «Didáctica del paisaje. Lo que es, lo que representa, cómo se vive».Íber. Didáctica de las Ciencas Sociales, Geografía e Historia, núm. 74, pp. 85-93.

Molina de la Torre, I., y J. M. ${ }^{a}$ Delgado Urrecho (2014): «Una estructura territorial contrastada», en L. C. Martínez Fernández y A. Moreno Mínguez (eds.): La provincia de Segovia. Interpretación del espacio y definición del modelo territorial. Diputación de Segovia, Segovia, pp. 353-414.

Ochaita, E., y J. A. HuERTAS (1989): «Desarrollo y aprendizaje del conocimiento espacial: aportaciones para la enseñanza del espacio geográfico». Boletín de la Asociación de Geógrafos Españoles, núm. 8, pp. 10-20.

Ortega y Gasset, J. (1906): «La pedagogía del paisaje». El Imparcial, 17 de septiembre de 1906.

Ortega ValCÁrcel, J. (2000): «El paisaje como construcción. El patrimonio territorial». DAU (Debats d'Arquitectura i Urbanisme), núm. 12, pp. 36-46.

Plaza Gutiérrez, J. I., M. I. Martín Jiménez, L. A. Hortelano Mínguez y R. Fernández Álvarez (2008): «Desarrollo territorial y cambios en las montañas interiores (factores, tendencias e iniciativas). Con- 
trastes y estudios de caso». Polígonos, núm. 18, pp. 155-191.

- M. ${ }^{a}$ I. Martín Jiménez, L. A. Hortelano Mínguez y R. FernÁndez Álvarez (2010): «Urbanización de la montaña. Intensidad y alcance del proceso; formas y paisajes inducidos en algunas comarcas del Sistema Central», en X Coloquio y Jornadas de Campo de Geografía Urbana. Espacios y paisajes urbanos. Reflexionar sobre su presente para proyectar su futuro. Asociación de Geógrafos Españoles/Universidad de Oviedo/Universidad de Cantabria/Universidad del País Vasco, Oviedo/Santander/Vitoria, pp. 289-303.

SAnz Herraiz, C. (1988): El relieve del Guadarrama oriental. Comunidad de Madrid, Madrid, 547 pp.

Solís Trapero, E. (2008): «El horizonte urbano madrileño: más allá de la región político-administrativa». Anales de Geografía, vol. 28, núm. 1, pp. 133-162.

- (2011): Del área metropolitana hacia la región urbana policéntrica madrileña: cambio de escala, estructura y articulación territorial. Tesis doctoral, Universidad Complutense de Madrid, Madrid, 783 pp.

Troitiño Vinuesa, M.A. (1990): «El Sistema Central», en A. Cabo Alonso y F. Manero Miguel (dirs.): Geografía de Castilla y León. T. 8, Ámbito, Valladolid, pp. 76-139.

Valenzuela, R. (1998): «Uso didáctico de fotografías aéreas». Enseñanza de las Ciencias de la Tierra, núm. 6 (2), pp. 172-173.

Velasco Romera, I. (2011): «La expansión del área urbana de Segovia. Transformación paisajística del entorno rural periurbano», en V. Gozálvez Pérez y J. A. Marco Molina (coords.): Geografía y desafíos territoriales en el siglo XXI. XXII Congreso de Geógrafos Españoles. Vol. 2, Asociación de Geógrafos Españoles/Universidad de Alicante, Alicante, pp. 779-790.

\section{FUENTES}

Association of Geographical Societies in Europe (EuGEO): Rome Declaration on Geographical Education in Europe. IV Eugeo Congress, Roma, 5 de septiembre de 2013.

Boletín Oficial de Castilla y León: Orden Edu/519/2014, de 17 de junio, por la que se establece el currículo y se regula la implantación, evaluación y desarrollo de la educación primaria en la Comunidad de Castilla y León, 20 de junio de 2014.

Boletín Oficial del Estado: Ley 25/1982, de 30 de junio, de Agricultura de Montaña, 12 de julio de 1982.

- Ley Orgánica 8/2013, de 9 de diciembre, para la Mejora de la Calidad Educativa, 10 de diciembre de 2013.

- Real decreto 126/2014, de 28 de febrero, por el que se establece el currículo básico de la Educación Primaria, 1 de marzo de 2014.

Centro de Información Territorial de la Junta de CasTILla y LeÓn (CIT) E InSTITUto Tecnológico Agrario de Castilla y León (itacyl): Archivo de ortofotos históricas (vuelo americano 1956-1957 y vuelo Iryda 1977-1983), ortofoto PNOA 2004 de Castilla y León y ortofoto PNOA 2014 de Castilla y León.

Instituto Geográfico Nacional (Ign) y Centro NacioNAL de Información Geográfica (CNIG): Siose. Sistema de Información sobre Ocupación del Suelo en España.

Instituto Nacional de Estadística (INE): Censo de población y viviendas.

- Padrón municipal de habitantes.

INTERNATIONAL GEOGRAPHIC UNION (UGI): Looking for an international strategy for geography education. Commission on Geographical Education of the International Geographic Union, Cracovia, agosto de 2014. 